\title{
RINOLIQUORRÉIA E HIDROCEFALIA POR GLIOSE DO AQUEDUTO CEREBRAI.
}

\author{
Walter C. Pereira*
}

A. Xavier de Lima Neto **

Rolando A. Tenuto ***

As fístulas de líquido cefalorraqueano não relacionadas a traumatismos craniencefálicos ocorrem raramente. Suas causas mais comuns são intervenções neurocirúrgicas ou erosões ósseas determinadas por neoplasia ou processo inflamatório crônico ${ }^{6,7}$; menos freqüentemente são conseqüentes a malformações congênitas $5,6,7,8$. A ventriculostomia espontânea, em casos extremos de hidrocefalia, é também relatada excepcionalmente ${ }^{9,10}$. Não encontramos, no entanto, nenhuma referência na literatura à ocorrência de fístula de líquido cefalorraqueano, secundária à erosão óssea determinada por hipertensão e dilatação do sistema ventricular, em casos de gliose do aqueduto cerebral. Êste fato justifica o registro de um caso que tivemos o ensejo de observar.

J.R.J., 15 anos de idade, sexo masculino, côr branca, registro H.C. 759.406. Internado em 1-7-66. História clínica iniciada 4 anos antes da internação com fraqueza nos membros inferiores e, um mês após, incapacidade para deambular sem apoio. Ao mesmo tempo os familiares notaram que o paciente comecou a apresentar crescimento excessivo da cabeça, queda acentuada da atividade intelectual e alterações do comportamento. Nos últimos dois anos tivera duas crises convulsivas generalizadas. Desde o início do quadro engordara excessivamente. Dois meses antes do ingresso no hospital começou a perder líquido incolor pela narina direita, o que foi interpretado como "resfriado"; quando em decúbito dorsal o liquido era deglutido, referindo o paciente sabor discretamente salgado. Desde então o déficit motor dos membros inferiores se atenuou, e o doente recomeçou a deambular sem apoio, embora com dificuldade. Antecedentes - Desenvolvimento motor aparentemente normal até os 11 anos de idade; quanto ao psiquismo, o paciente conseguira, até aquela idade, cursar os três primeiros anos do curso elementar, sendo reprovado duas vêzes. Exame clínico-neurológico - Paciente obeso e com hipodesenvolvimento dos órgãos genitais externos; distribuiçâo da gordura e dos pêlos pubianos do tipo feminino. Macrocefalia acentuada: perímetro craniano de $63 \mathrm{~cm}$. Som de "pote rachado" à percussão do crânio. Perda de líquido límpido e incolor pela narina direita nas posiçōes ortostática, sentada e em decúbito lateral direito. Rebaixa-

Trabalho da Clínica Neurológica da Faculdade de Medicina da Universidade de Sāo Paulo (Prố. Adherbal Tolosa): * Neurocirurgião; ** Médico-estagiário; *** Neurocirurgiāo-chefe. 
mento psíquico evidente, com déficit mais acentuado da memória de fixação e do raciocinio; agressividade em relação aos familiares e companheiros de enfermaria. Dificuldade à marcha, caminhando com passos curtos e indecisos; paraparesia crural motora; sinal de Babinski à esquerda; atrofia e discreta hipertonia em extensão dos membros inferiores. Fundos oculares normais. No restante o exame neurológico se mostrava sem alterações.

Exames complementares - Craniograma: macrocefalia; aumento das impressōes digitiformes e alterações selares conseqüentes à hipertensão intracraniana. L'letrencefalograma: ondas lentas de 3 a $4 \mathrm{c} / \mathrm{seg}$, quase continuas, difusas, predominando nas regiões frontais. Liquido cefalorraqueano ( $S O D$ ): pressão inicial de $11 \mathrm{~cm}$ de água (manômetro de Claude); aspecto límpido e incolor; 4 leucócitos por $\mathrm{mm}^{3} ; 47 \mathrm{mg}$ de proteinas por $100 \mathrm{ml}$ (VDRL); $700 \mathrm{mg}$ de cloretos por $100 \mathrm{ml}$; $74 \mathrm{mg}$ de glicose por $100 \mathrm{ml}$; Pandy e Nonne opalescentes; Takata-Ara negativo. Angiografia pela artéria carótida direita: sinais indiretos de dilatação ventricular. lodoventriculografia: bloqueio do sistema ventricular ao nível da transição $3^{\circ}$ ventrículo-aqueduto cerebral; presenca de lipiodol no interior do seio esfenoidal e das fossas nasais (figura 1 ).

Em 4-8-66 o paciente foi submetido à derivação ventriculo-peritoneal, com interposição de válvula de Holter, para evitar que o ulterior tamponamento da fistula provocasse recidiva da hipertensão do sistema ventricular a montante do bloqueio. Em 10-8-66 foi feita craniotomia frontal direita para correção da comunicacāo anômala da sela turca com o seio esfenoidal, observada na iodoventriculografia. Foi encontrada, durante o ato cirúrgico, franca comunicação entre o assoalho do $3^{*}$ ventriculo, provàvelmente o recesso supra-óptico, com a parte posterior do seio esfenoidal, mediante larga erosão da sela turca. As aderências entre estas duas estruturas, que formavam o trajeto fistuloso, foram desfeitas, sendo a falha óssea bloqueada com fragmentos do músculo temporal. O pós-operatório decorreu sem incidentes, cessando inteiramente a rinoliquorréia. O paciente teve alta 10 dias após a segunda intervenção cirúrgica, e continua sendo acompanhado no ambulatório, sem recidiva da fistula.

\section{COMENTARIOS}

O aparecimento de hidrocefalia tardiamente, em adolescentes ou adultos jovens, é uma das características da gliose do aqueduto cerebral $3, ?$. Russell ${ }^{9}$ descreve esta condição como sendo uma proliferação lenta e progressiva da glia subependimária que invade a luz do aqueduto trabeculando-o e, por fim, obstruindo-o. O mesmo processo ocorre no restante do sistema ventricular, porém, em virtude da maior amplitude de sua luz, não determina qualquer sintomatologia. A referida autora julga tratar-se de processo de natureza inflamatória, embora outros autores admitam também origem congênita ou neoplásica ${ }^{3}$. No caso que relatamos, o aparecimento da hidrocefalia foi tardio, assim como a evidente descompensação da hipertensão intracraniana após os 11 anos de idade. Tais fatos nọs levaram a admitir tratar-se de um caso de gliose do aqueduto. A iodoventriculografia reforçou bastante essa hipótese, demonstrando imagem fortemente sugestiva dessa afecção ${ }^{1,9,12}$.

O aspecto insólito da nossa observação foi a ocorrência de rinoliquorréia, determinada pela comunicação do $3 .^{\circ}$ ventrículo com o seio esfenoidal. Tal fato pode ser explicado admitindo-se que a pronunciada compressão da sela turca, pelo $3 .^{\circ}$ ventrículo dilatado e hipertenso, determinou solução de continuidade do assoalho selar. Ao mesmo tempo houve rotura da pa- 



Fig. 1 - Caso J.R.J. Ventriculografia com lipiodol: em A, observa-se o aqueduto cerebral interrompido em sua porção inicial; em $B$, a seta da direita aponta o contraste passando do $3^{\circ}$ ventrículo para o interior do seio esfenoidal $e$ a seta da esquerda mostra gotas de lipiodol nas fossas nasais. 
rede ventricular, estabelecendo-se a fístula. Ventriculostomias espontâneas têm sido relatadas por outros autores como conseqüência de graus extremos de hidrocefalia 9, 10. Meyer (citado por Russell ") descreve um caso de rinoliquorréia intermitente, determinada por tumor da glândula pineal, no qual houve perfuração do seio frontal e rotura do corno frontal do ventrículo lateral. Este caso parece-nos ser o único registrado na literatura que, em alguns aspectos, se assemelha com o que relatamos. Outro pormenor interessante é o da localização da fístula por meio da iodoventriculografia. O contraste positivo tem sido empregado por vários autores para a localização exata de fístulas de líquido cefalorraqueano $2,4,7,8,11,1 \%$. Este aspecto é de grande importância prática para a planificação segura do ato cirúrgico, visando a correção de tais fístulas.

\section{RESUMO}

E relatado um caso de hidrocefalia tardia, determinada por gliose do aqueduto cerebral, complicada com rinoliquorréia. A fístula do líquido cefalorraqueano se estabcleceu em consequiência da erosão da sela turca pelo assoalho do $3 .^{\circ}$ ventriculo hipertenso e dilatado, determinando comunicação entre a cavidade ventricular e o seio esfenoidal. $O$ paciente foi operado, tendo a fistula sido ocluída satisfatỏriamente; prèviamente foi feita derivaçāo ventrículo-peritoneal para evitar recidiva da hipertensão do sistema ventricular.

\section{SUMMARY}

Cerebrospinal fluid rhinorrhea and hydrocephalus due to gliosis of the cerebral aqueduct. Report of a case

A case of late hydrocephalus due to gliosis of the cerebral aqueduct, complicated with cerebrospinal fluid rhinorrhea, is reported. The fistula was formed by a large communication between the very dilated $3^{\text {rd }}$ ventricle and the sphenoidal sinus, in consequence to a erosin of the sellar floor. The patient was operated on and the fistula satisfactority blocked; previously was made a ventriculo-peritoneal shunt to avoid the recurrence of the ventricular hypertension.

\section{REFERENCIAS}

1. ELVIDGE, A. R. - Treatment of obstructive lesions of the aqueduct of Sylvius and the fourth ventricle by interventriculostomy. J. Neurosurg. 24:11-23, 1966.

2. GHOURALAL, S.; MYERS, P. W. \& CAMPBELL, E. - Persistent cerebrospinal rhinorrhea originating in fracture through petrous bone and cured by muscle graft: report of a case. J. Neurosurg. 13:205-207, 1956.

3. INGRAHAM, F. D. \& MATSON, D. D. - Neurosurgery of Infancy and Childhood. Charles C. Thomas, Springfield, 1954, págs. 121-122.

4. JUNGMANN, A. \& PEYSER, E. - Roentgen visualization of cerebrospinal fluid fistula with contrast medium. Radiology 80:92-95, 1963. 
5. KLINE, O. R. - Spontaneous cerebrospinal otorrhea. Arch. Otolaryng. 18: 34-39, 1933.

6. NENZELIUS, C. - On spontaneous cerebrospinal otorrhea due to congenital malformations. Acta Otolaryng. 39:314-328, 1951.

7. PRIBAM, H. F. W.; HASS, A. C. \& NISHIOKA, H. - Radiographic localization of a spontaneous cerebrospinal fluid fistula. Case report. J. Neurosurg. 24: 1031-1033, 1966.

8. ROCKETT, F. X.; WitTenborG, M. H.; SHillito, J. Jr. \& MATSON, D. D. - Pantopaque visualization of a congenital dural defect of a internal auditory meatus causing rhinorrhea. Report of a case. Amer. J. Roentgenol. $91: 640-646,1964$.

9. RUSSELL, D. S. - Observations on the Pathology of Hydrocephalus. Privy Council. Medical Research Council Special Series, Londres, 1949, págs. 41-50.

10. SWEET, W. H. - Spontaneous cerebral ventriculostomium. Arch. Neurol. Psychiat. 44:532-540, 1940.

11. TENG, P. \& EDAlatpouR, N. - Cerebrospinal fluid rhinorrhea with demonstration of cranionasal fistula with pantopaque. Radiology 81:802-806, 1963.

12. TURNBULL, I. M. \& DRAKE, C. G. - Membranous occlusion of the aqueduct of Sylvius. J. Neurosurg. 24:24-33, 1966.

Clinica Neurológica - Hospital das Clinicas da Fac. Med. du Univ. de Sĩo Punlo Caixa Postal 3461 - São Paulo, SP - Bircsil. 